\title{
Ultrasonography surveillance improves prognosis of patients with hepatocellular carcinoma
}

\author{
HIROKA YAMAGO $^{1}$, ATSUSHI HIRAOKA ${ }^{1}$, TAISEI MURAKAMI ${ }^{1}$, HIROFUMI IZUMOTO $^{1}$, HIDETARO UEKI $^{1}$, \\ MARIE OCHI ${ }^{1}$, TOSHIHIKO AIBIKI ${ }^{1}$, TOMONARI OKUDAIRA ${ }^{1}$, RYUICHIRO IWASAKI ${ }^{1}$, YOSHIFUMI SUGA ${ }^{1}$, \\ KENICHIRO MORI $^{1}$, HIDEKI MIYATA ${ }^{1}$, EIJI TSUBOUCHI ${ }^{1}$, MASATO KISHIDA ${ }^{1}$, MASASHI HIROOKA ${ }^{2}$, \\ MASANORI ABE ${ }^{2}$, BUNZO MATSUURA ${ }^{2}$, TOMOYUKI NINOMIYA ${ }^{1}$, YOICHI HIASA ${ }^{2}$ and KOJIRO MICHITAKA ${ }^{1}$ \\ ${ }^{1}$ Gastroenterology Center, Ehime Prefectural Central Hospital, Matsuyama, Ehime 790-0024; \\ ${ }^{2}$ Department of Gastroenterology and Metabology, Ehime University Graduate School of Medicine, \\ Toon, Ehime 791-0295, Japan
}

Received October 1, 2018; Accepted April 22, 2019

DOI: $10.3892 /$ mco.2019.1888

\begin{abstract}
To examine the effectiveness of ultrasonography (US) for hepatocellular carcinoma (HCC) surveillance, the prognosis of HCC patients who underwent such screening at an expert medical institution or at general clinics were analyzed, as well as those without US surveillance. From October 2006 to December 2014, 872 patients with naïve HCC were enrolled and divided into the surveillance (S)-group $(n=398)$, who underwent follow-up examinations with US, and the non-S group $(n=474)$. The $S$-group was further subdivided into patients who underwent follow-up surveillance at Ehime Prefectural Central Hospital, an expert medical institution (SE-group, $n=189$ ), and those who received surveillance at general clinics (SG-group, $n=209$ ). Prognosis and clinical characteristics were analyzed. In the non-S group, the frequency of patients without viral hepatitis (NBNC-HCC) and Tumor, Node, Metastasis stage was greater. As a result, the median survival time (MST) of the non-S group was reduced, compared with the $\mathrm{S}$ group (non-S group, 34.1 vs. $\mathrm{S}$ group, 68.2 months; $\mathrm{P}<0.001)$. Tumor size was significantly different between the SE- and SG-groups (SE-group, 2.0 \pm 1.0 vs. SG-group, $2.5 \pm 1.3 \mathrm{~cm} ; \mathrm{P}<0.001$ ), whereas tumor number (SE-group: $1.5 \pm 1.1$ vs. SG-group, $1.7 \pm 1.2 ; \mathrm{P}=0.164$ ) and MST (SE-group, 72.1 vs. SG-group, 67.1 months; $\mathrm{P}=0.931$ ) were not significantly different. Surveillance performed at either an expert medical institution or general clinic improved the prognosis of HCC patients. Dissemination of findings demonstrating the importance of surveillance for HCC to all clinicians as well as patients with chronic liver disease
\end{abstract}

Correspondence to: Dr Atsushi Hiraoka, Gastroenterology Center, Ehime Prefectural Central Hospital, 83 Kasuga-cho, Matsuyama, Ehime 790-0024, Japan

E-mail: hirage@m.ehime-u.ac.jp

Key words: hepatocellular carcinoma, surveillance, ultrasonography is important, and establishment of an effective surveillance strategy for NBNC-HCC is required.

\section{Introduction}

Hepatocellular carcinoma (HCC), one of the most commonly occurring malignant tumors worldwide $(1,2)$, often develops in patients with hepatitis $\mathrm{C}$ virus $(\mathrm{HCV})$ or hepatitis $\mathrm{B}$ virus (HBV) infection $(3,4)$, who are defined as high-risk for HCC and are recommended to undergo protocol screening for tumor development with a surveillance program. Detection of HCC at an early stage is important to improve patient prognosis, as tumor burden is an important prognostic factor along with hepatic reserve function (5-7). The progression of surgical resection (8) and/or radiofrequency ablation (RFA) $(9,10)$ as curative treatments have improved patient prognosis when diagnosed at an earlier stage. In addition, the development of tyrosine kinase inhibitors (11-14) has contributed to a better HCC prognosis in patients who are allocated an unresectable status. Ultrasonography (US) is a popular and economical examination method that does not involve X-ray exposure, which is deemed to be suitable for HCC surveillance. Early stage HCC diagnosis is important for treatment (15), meaning that a suitable surveillance program should be evaluated.

Although the surveillance program for $\mathrm{HCC}$, which primarily utilizes US, has been performed in patients with a high risk of HCC in Japan, few reports of surveillance efficacy for the improvement of prognosis have been performed. Only a limited number of studies have examined the effectiveness of HCC surveillance performed at regional hub hospitals in Japan (16). Herein, the outcomes of HCC patients with and without surveillance using with US were analyzed to elucidate its usefulness and impact for improving prognosis.

\section{Materials and methods}

Patients and definition of surveillance for HCC. The records of 872 patients with naïve $\mathrm{HCC}$ who were examined from October 2006 to December 2014 were analyzed, following the 
exclusion of 170 cases without information regarding HCC surveillance. The enrolled patients were divided into those who did (S-group, $n=398$ ) and did not (non-S group, $n=474$ ) undergo surveillance. In addition, the S-group was divided into two sub-groups: i) Those who underwent surveillance at Ehime Prefectural Central Hospital (EPCH), an expert medical institution (SE-group, $\mathrm{n}=189$ ); and ii) those who received surveillance at general clinics (SG-group, $n=209$; Fig. 1). Patients whose surveillance of HCC was performed only with AFP examination or whose $\mathrm{HCC}$ was pointed out incidentally were classified as the non-S group. The outcomes and clinical characteristics of the $\mathrm{S}$ - and non-S groups were compared in a retrospective manner, while those of the SEand SG-groups were also compared as a sub-analysis.

Surveillance program. EPCH is a qualified regional hub hospital, where surveillance for $\mathrm{HCC}$ is performed for a fixed interval ( 3 or 6 months) with US and $\alpha$-fetoprotein (AFP) in accordance with liver disease grade [chronic hepatitis $(\mathrm{CH} ; \mathrm{n}=200)$ or liver cirrhosis ( $\mathrm{LC} ; \mathrm{n}=198)$ ], following practical guidelines for HCC used in Japan since $2005(17,18)$.

Diagnosis of HCC. When HCC is suspected based on US findings, contrast enhanced US (CEUS), dynamic CT, or gadolinium-ethoxybenzyl-diethylenetriamine pentaacetic acid (Gd-EOB-DTPA)-enhanced magnetic resonance imaging (EOB-MRI) (19) was typically performed as an additional examination. HCC was diagnosed in patients based on increasing AFP expression, as well as dynamic CT (20), magnetic resonance imaging (MRI), and/or CEUS with perflubutane (Sonazoid ${ }^{\circledR}$; Daiichi Sankyo Co., Ltd., Tokyo, Japan) $(21,22)$ findings. Tumor, Node, Metastasis (TNM) stage was determined according to the Liver Cancer Study Group of Japan, 6th edition (23).

The study protocol was conducted in compliance with the Helsinki Declaration and was approved by the Institutional Ethics Committee of EPCH (approval no. 26-11). Values are expressed as the mean \pm standard deviation. Statistical analyses were performed using Student's t test, Welch's test, Fischer's exact test, Mann-Whitney's U test, and the Kaplan-Meier method with a log-rank test using EZR version 1.29 (24), a graphical user interface for $\mathrm{R}$ (The R Foundation for Statistical Computing, Vienna, Austria). $\mathrm{P}<0.05$ was considered to indicate a statistically significant difference.

\section{Results}

Although age was not significantly different between the $\mathrm{S}-(\mathrm{n}=398)$ and non- $\mathrm{S}(\mathrm{n}=474)$ groups $(\mathrm{S}, 70.2 \pm 9.2$ vs. non-S, $70.4 \pm 10.7$ years; $\mathrm{P}=0.689$ ), the frequency of male gender (S, 66.1\% vs. non-S, 76.8\%; $\mathrm{P}<0.001$ ), surgical resection (S, $21.1 \%$ vs. non-S, 31.4\%; P<0.001), NBNC-HCC (S, $14.5 \%$ vs. non-S, $36.7 \%$; $\mathrm{P}<0.001$ ), lower grade of Child-Pugh classification (B and C; S, 23.1\% vs. non-S, 36.4\%; $\mathrm{P}<0.001$ ), and TNM stage IV (S, 1.3\% vs. non-S, 29.1\%; $\mathrm{P}<0.001$ ) was greater, while tumor size $(\mathrm{S}, 2.3 \pm 1.2$ vs. non $-\mathrm{S}, 5.4 \pm 3.7 \mathrm{~cm}$; $\mathrm{P}<0.001)$ and tumor number $(\mathrm{S}, 1.6 \pm 1.1$ vs. non- $\mathrm{S}, 2.5 \pm 2.0$; $\mathrm{P}<0.001)$ were significantly larger in the non-S group. Furthermore, those non-S patients had higher levels of tumor markers, including AFP (S, 201.8 $\pm 1228.6 \mathrm{ng} / \mathrm{ml}$ vs. non-S,

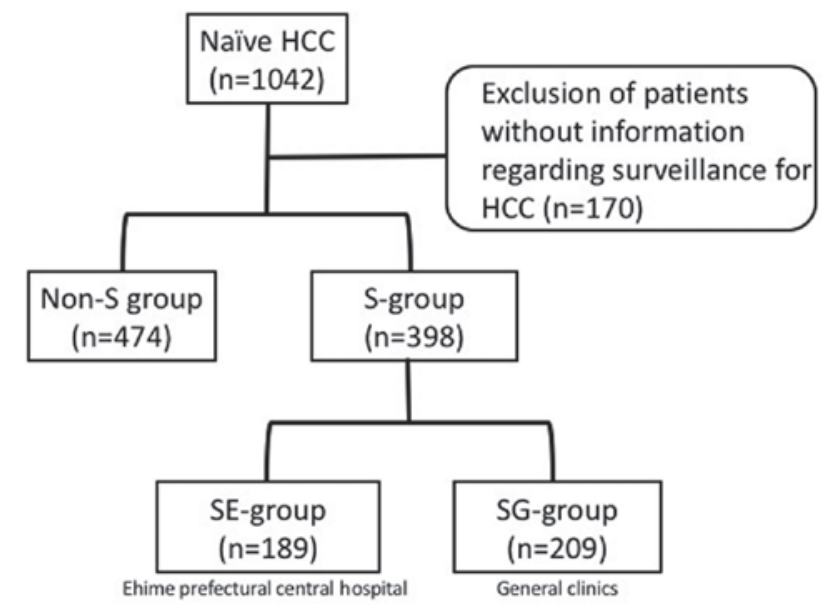

Figure 1. Patients with naïve HCC enrolled in the present study. In total, 872 patients with naïve HCC were enrolled, who were examined from October 2006 to December 2014, following the exclusion of cases without information regarding surveillance findings. They were divided into those who did (S-group, $\mathrm{n}=398$ ) and did not (non-S group, $\mathrm{n}=474$ ) undergo surveillance. The S-group was further subdivided into patients who underwent surveillance at Ehime Prefectural Central Hospital (SE-group, $n=189$ ) and general clinics (SG-group, n-209). HCC, hepatocellular carcinoma; S-group, surveillance group; non-S, non-surveillance group; SE-group, follow-up surveillance at Ehime Prefectural Central Hospital; SG-group, follow-up surveillance at general clinics.

$15,123.4 \pm 77,037.9 \mathrm{ng} / \mathrm{ml} ; \mathrm{P}<0.001$ ), fucosylated-AFP (AFP-L3; S, $9.2 \pm 17.0 \%$ vs. non-S, $19.9 \pm 25.8 \%$; $P<0.001)$, des- $\gamma$-carboxy prothrombin (DCP; S, 757.2 $\pm 4918.0 \mathrm{mAU} / \mathrm{ml}$ vs. non-S, $17,472.5 \pm 46,451.4 \mathrm{mAU} / \mathrm{ml} ; \mathrm{P}<0.001$; Table I). In addition, the overall survival rate (OSR) after 1 (S, 91.6\% vs. non-S, 71.8\%), 3 (S, $75.3 \%$ vs. non-S, $47.8 \%$ ) and 5 years (S, $55.2 \%$ vs. non-S, $34.7 \%$ ) was significantly higher in the $\mathrm{S}$ group, compared with the non-S group, as was median survival time (MST; S, 68.2 vs. non-S, 34.1 months; $\mathrm{P}<0.001$; Fig. 2).

Sub-analyses were also performed for comparison of patient characteristics and prognosis. The S-group was divided into those who underwent surveillance at $\mathrm{EPCH}$, an expert medical institution (SE-group, $\mathrm{n}=189$ ), and at a general clinic (SG-group, $n=209$ ). It was determined that average age was older (SG-group, $71.4 \pm 8.8$ vs. SE-group, $68.8 \pm 9.5$ years), tumor size was larger (SG-group, $2.5 \pm 1.3$ vs. SE-group, $2.0 \pm 1.0 \mathrm{~cm}$ ), and frequency of TNM stage II and III (SG-group, 71.8 vs. SE-group, 52.9\%) was greater in the SG-group (all $\mathrm{P}<0.001$; Table II). Although there were significant differences in tumor size and frequency of TNM stage II and III, tumor number was not significantly different (SE-group, $1.5 \pm 1.1$ vs. SG-group, $1.7 \pm 1.2 ; \mathrm{P}=0.164)$. As a result, the 1-, 3- and 5-year OSR (SG-group, 92.4, 76.0 and 55.8\% vs. SE-group, 90.8, 74.5 and $54.6 \%$, respectively) and MST (SG-group, 67.1 vs. SE-group, 72.1 months) were not significantly different between the SGand SE-groups ( $\mathrm{P}=0.931$; Fig. 3).

\section{Discussion}

Surveillance for HCC in high-risk patients, such as those with viral hepatitis or LC has been expected to improved patient prognosis due to earlier tumor detection. There are a number of reasons why a surveillance program improves prognosis, 
Table I. Comparison for the characteristics of S- and non-S group.

\begin{tabular}{lccr}
\hline Patient characteristics & S-group (n=398) & Non-S group (n=474) & P-value \\
\hline Age (years) & $70.2 \pm 9.2$ & $70.4 \pm 10.7$ & 0.689 \\
Gender (male:female) & $263: 135$ & $364: 110$ & $<0.001$ \\
Etiology (HCV:HBV:HBV+HCV:NBNC) & $310: 25: 5: 58$ & $250: 46: 4: 174$ & 7 \\
Number of HCV patients obtained SVR & 8 & 0 & 1.000 \\
Number of HBV patients treated with NA & 18 & $5.4 \pm 3.7$ & $<0.001$ \\
Maximum tumor diameter (cm) & $2.3 \pm 1.2$ & $2.5 \pm 2.0$ & $<0.001$ \\
Tumor number & $1.6 \pm 1.1$ & $15,123.4 \pm 77,037.9$ & $<0.001$ \\
AFP (ng/ml) & $201.8 \pm 1228.6$ & $19.9 \pm 25.8$ & $<0.001$ \\
AFP-L3 (\%) & $9.2 \pm 17.0$ & $17,472.5 \pm 46,451.4$ & $<0.001$ \\
DCP (mAU/ml) & $757.2 \pm 4918.0$ & $301: 123: 50$ & $<0.001$ \\
Child-Pugh classification (A:B:C) & $306: 78: 14$ & $42: 172: 122: 138$ & $<0.001$ \\
TNM classification of LCSGJ 6th (I:II:III:IV) & $143: 183: 67: 5$ & $26: 139: 119: 113: 54: 23$ & $<0.001$ \\
JIS score (0:1:2:3:4:5) & $115: 161: 91: 27: 3: 1$ & $149: 64: 1: 260$ & $<0.001$ \\
Treatment (resection:RFA:PEIT:others) & $84: 246: 2: 66$ & 34.1 & $<0.001$ \\
MST (months) & 68.2 & & \\
\hline
\end{tabular}

$\mathrm{HCV}$, hepatitis C virus; HBV, hepatitis B virus; NBNC, negative for both $\mathrm{HCV}$ and $\mathrm{HCV}$; SVR, sustained virological response; NA, nucleotide analogue; AFP, $\alpha$-fetoprotein; AFP-L3, fucosylated AFP; DCP, des- $\gamma$-carboxy prothrombin; TNM, tumor node metastasis stage; LCSGJ 6th, Liver Cancer Study Group of Japan 6th edition; JIS, Japan Integrated Staging Score; RFA, radiofrequency ablation; PEIT, percutaneous ethanol injection therapy; MST, median survival time.

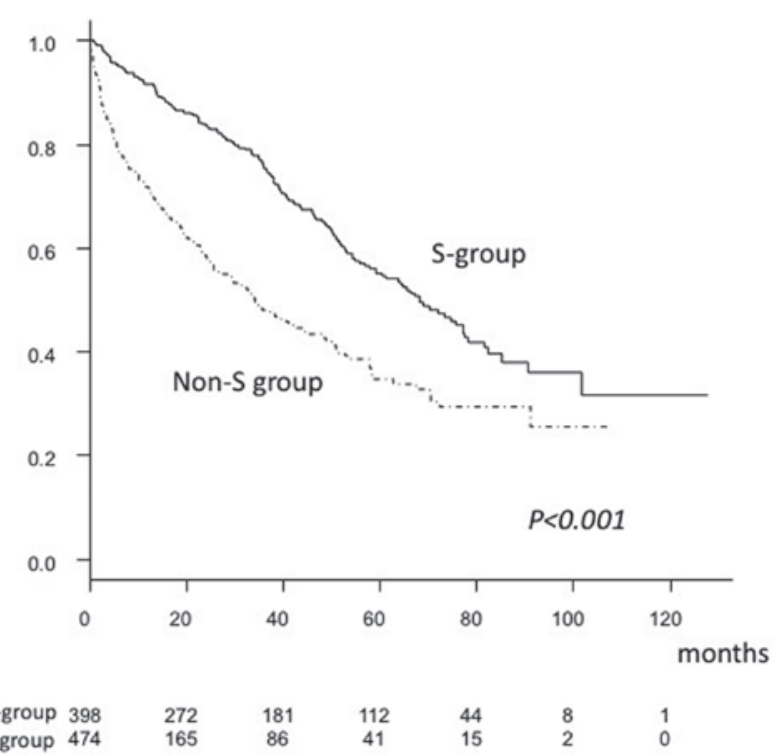

Figure 2. Overall survival of patients in the S- and non-S groups. The overall survival rate after 1,3 , and 5 years, as well as median survival time of the $\mathrm{S}$-group were higher than that of the non-S group $(\mathrm{P}<0.001)$. group, surveillance group; non-S, non-surveillance group.

including advancements in imaging modalities such as CEUS $(21,22,25)$ and EOB-MRI (19), allowing the rapid detection and diagnosis of smaller HCC. In addition, the development of therapeutic modalities and assistance methods with low invasiveness, such as RFA (10,26), virtual US (VUS) (27), and artificial effusion in RFA (28) have bettered small HCC treatment. Surveillance for smaller HCC detection in high-risk patients is important to increase the likelihood of successful curative treatment, thus obtaining a better prognosis.

Singal et al (29), reported that the combination of US and AFP maximizes the sensitivity for HCC detection at an early stage, compared to surveillance with US or AFP alone (combination, US alone, AFP alone sensitivity: 90, 44 and 66\%, respectively; specificity: 83, 92 and 91\%, respectively) (29). In a randomized control trial (RCT), it was demonstrated that biannual screening for HCC with US and AFP in HBV patients reduced mortality by $37 \%$, as compared to the control group that did not undergo screening (30). In addition, surveillance with US and AFP in patients with LC significantly improved survival as compared to patients with incidentally detected HCC (15). On the other hand, in another report, biannual AFP screening in HBV patients did not result in an overall reduction in mortality (31). Thus, it is thought that surveillance with both US and AFP is most effective. Costentin et al (32) reported that compliance with HCC surveillance guidelines (fewer than 7 months between image evaluations) lead to early diagnosis, allocation of curative treatment, and a longer adjusted OS of patients with compensated $\mathrm{HCV}$ - or $\mathrm{HBV}$-associated cirrhosis and a diagnosis of HCC (32). In the present study, average tumor size of the SG-group was larger than that of the SE-group $(\mathrm{P}<0.001)$. This result may have depended on an easier access system to CEUS, CT or MRI in the SE-group. However, the frequency of curative treatments (resection, RFA and PEIT) did not show a significant difference between the groups, and prognosis was similar. Surveillance with US and AFP improves the prognosis of patients with chronic liver disease. The clinical usefulness of AFP-L3 and DCP other than AFP as tumor markers for HCC surveillance should be examined in additional future studies. Lead-time bias should be taken into 
Table II. Characteristics of SE- and SG-groups.

\begin{tabular}{lccr}
\hline Patient characteristics & SE-group (n=189) & SG-group (n=209) & P-value \\
\hline Age (years) & $68.8 \pm 9.5$ & $71.4 \pm 8.8$ & $<0.001$ \\
Gender (male:female) & $120: 69$ & $143: 66$ & 0.301 \\
Etiology (HCV:HBV:HBV\&HCV:NBNC) & $141: 12: 2: 34$ & $168: 13: 3: 25$ & 0.204 \\
Number of HCV patients obtained SVR & 6 & 2 & 0.145 \\
Number of HBV patients treated with NA & 11 & 7 & 0.073 \\
Maximum tumor diameter (cm) & $2.0 \pm 1.0$ & $2.5 \pm 1.3$ & $<0.001$ \\
Tumor number & $1.5 \pm 1.1$ & $1.7 \pm 1.2$ & 0.164 \\
AFP (ng/ml) & $169.0 \pm 929.5$ & $231.3 \pm 1447.5$ & 0.614 \\
AFP-L3 (\%) & $7.4 \pm 13.4$ & $10.7 \pm 19.6$ & 0.055 \\
DCP (mAU/ml) & $369.5 \pm 1812.9$ & $1107.0 \pm 6549.6$ & 0.130 \\
Child-Pugh classification (A:B:C) & $140: 42: 7$ & $166: 36: 7$ & 0.218 \\
TNM classification of LCSGJ 6th (I:II:III:IV) & $88: 77: 23: 1$ & $55: 106: 44: 4$ & $<0.001$ \\
JIS score (0:1:2:3:4:5) & $68: 72: 39: 8: 1: 1$ & $47: 89: 52: 19: 2: 0$ & 0.003 \\
Treatment (resection:RFA:PEIT:others) & $34: 125: 1: 29$ & $50: 121: 1: 37$ & 0.540 \\
MST (months) & 72.1 & 67.1 & 0.931 \\
\hline
\end{tabular}

$\mathrm{HCV}$, hepatitis C virus; HBV, hepatitis B virus; NBNC, negative for both $\mathrm{HCV}$ and $\mathrm{HCV}$; SVR, sustained virological response; NA, nucleotide analogue; AFP, $\alpha$-fetoprotein; AFP-L3, fucosylated AFP; DCP, des- $\gamma$-carboxy prothrombin; TNM, tumor node metastasis stage; LCSGJ 6th, Liver Cancer Study Group of Japan 6th edition; JIS, Japan Integrated Staging Score; RFA, radiofrequency ablation; PEIT, percutaneous ethanol injection therapy; MST, median survival time; SE-group, follow-up surveillance at Ehime Prefectural Central Hospital; SG-group, follow-up surveillance at general clinics.

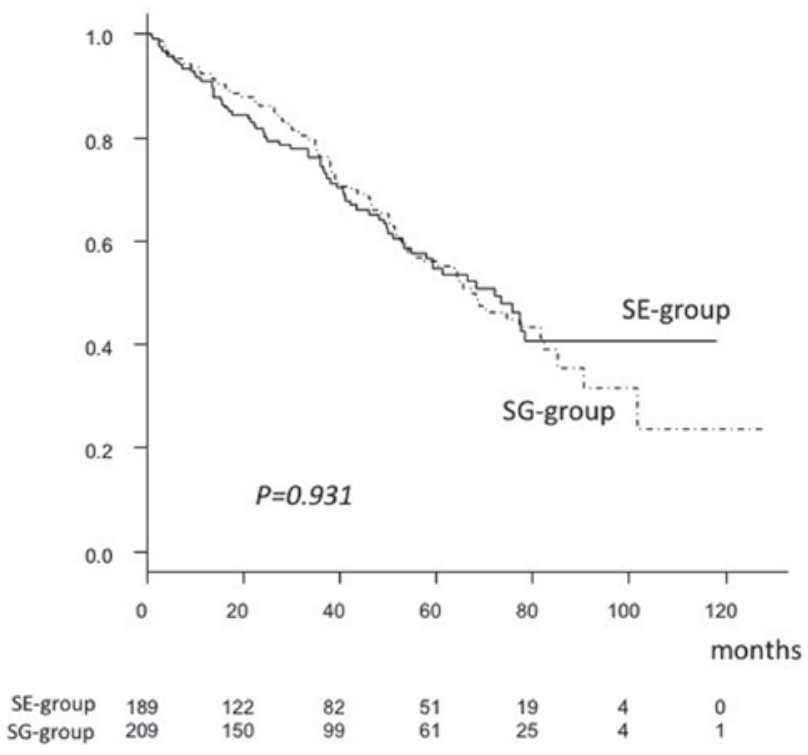

Figure 3. Overall survival of patients in the SE- and SG-groups. The overall survival rate after 1,3 , and 5 years, and median survival time were not significantly different between the groups $(\mathrm{P}=0.931)$.

consideration for this type of investigation. Toyoda et al (33) reported that the surveillance group exhibited a significantly better survival than the non-surveillance group after adjusting for lead-time bias (MST: Surveillance vs. non-surveillance group, 7.18 vs. 5.65 years; $\mathrm{P}<0.0001$ ). Further study is required to confirm the influence of lead-time bias to survival.

In the present cohort, the frequency of NBNC-HCC was greater in the non-S group, compared with the S-group.
Along with an increasing aging population in Japan, the frequency of patients without HCV or HBV (NBNC-HCC) has increased (34-36), thus establishment of a method for identifying affected patients without viral hepatitis or alcohol abuse is becoming increasingly important. Recently, non-alcoholic steatohepatitis (NASH) has been recognized to increase the risk for development of HCC; therefore, patients with NASH must be enrolled in a HCC screening program (37). Nevertheless, many patients with diabetes mellitus (DM), who often also have NASH, are receiving regular medical check-ups at local clinics. To control DM, it may be possible to focus high-risk patients, who require HCC surveillance with US, from those with DM. It has been proposed that age and fibrosis- 4 index $(38,39)$ are factors that indicate individuals at high risk for HCC among DM patients without alcohol abuse (alcohol intake: $>60 \mathrm{~g} /$ day) (37). Additional investigations to form a surveillance strategy for detection of HCC at an earlier stage in patients without viral hepatitis or alcohol abuse are required.

US is easily introduced due to its lower cost relative to other radiological modalities, such as enhancedCT andEOB-MRI(40). Furthermore, examinations may be repeatedly performed, although some issues remain. The accuracy of US findings for HCC surveillance is strongly dependent on the quality of the equipment and expertise of the performing operator (41), thus special training is warranted for ultrasonographers. Although tumor diameter and TNM stage in the SG-group of the present study were greater compared with the SE-group, tumor number and OSR were not significantly different between those groups. It was speculated that the reason why repeated surveillance screening for HCC using the combination of US and AFP was effective, was because of the increased chance for detection of 
smaller sized and fewer tumors, resulting in the possibility to be treated with a curative method.

The present study has certain limitations. First, the present study was retrospective. Second, the quality of US examination of each institution could not be exactly compared. Additional analyses with a prospective study or RCT, if possible, are required. However, physicians and their patients should be notified of the importance of surveillance for HCC with a combination of US and AFP for high-risk patients with viral hepatitis and/or alcohol abuse. In addition, management of high-risk patients without viral hepatitis or alcohol abuse is necessary. It was concluded that repeated surveillance with US and AFP leads to diagnosis of HCC at an earlier stage, and improved prognosis of affected patients compared with patients who did not undergo surveillance.

\section{Acknowledgements}

Not applicable.

\section{Funding}

No funding was received.

\section{Availability of data and materials}

The datasets of this study are not publicly available, but are available from the corresponding author on reasonable request.

\section{Authors' contributions}

$\mathrm{AH}$ and $\mathrm{HY}$ conceived the present study, analyzed the data and wrote the manuscript. YH, BM, AM and MH conceived, reviewed and edited the manuscript of the current study. TM, HI, HU, MO, TA, TO, RI, YS, KMo, HM, ET, MK, TN and $\mathrm{KMi}$ acquired the data.

\section{Ethics approval and consent to participate}

The study protocol was conducted in compliance with the Helsinki Declaration and was approved by the Institutional Ethics Committee of EPCH (approval no. 26-11).

\section{Patient consent for publication}

Not applicable.

\section{Competing interests}

The authors declare that they have no competing interests.

\section{References}

1. Song TJ, Ip EW and Fong Y: Hepatocellular carcinoma: Current surgical management. Gastroenterology 127 (5 Suppl 1): S248-S260, 2004

2. Parkin DM, Bray F, Ferlay J and Pisani P: Global cancer statistics, 2002. CA Cancer J Clin 55: 74-108, 2005.

3. Hiraoka A, Hidaka S, Shimizu Y, Utsunomiya H, Imai Y, Tatsukawa H, Tazuya N, Yamago H, Yorimitsu N, Tanihira T, et al: Recent trends of Japanese hepatocellular carcinoma due to HCV in aging society. Hepatogastroenterology 59: 1893-1895, 2012.
4. Tada T, Kumada T, Toyoda H, Tsuji K, Hiraoka A and Tanaka J: Impact of FIB-4 index on hepatocellular carcinoma incidence during nucleos(t)ide analogue therapy in patients with chronic hepatitis B: An analysis using time-dependent receiver operating characteristic. J Gastroenterol Hepatol 32: 451-458, 2017.

5. Kudo M, Chung H, Haji S, Osaki Y, Oka H, Seki T, Kasugai H, Sasaki Y and Matsunaga T: Validation of a new prognostic staging system for hepatocellular carcinoma: The JIS score compared with the CLIP score. Hepatology 40: 1396-1405, 2004.

6. Hiraoka A, Kumada T, Michitaka K, Toyoda H, Tada T, Ueki H, Kaneto M, Aibiki T, Okudaira T, Kawakami T, et al: Usefulness of albumin-bilirubin grade for evaluation of prognosis of 2584 Japanese patients with hepatocellular carcinoma. J Gastroenterol Hepatol 31: 1031-1036, 2016.

7. Hiraoka A, Kumada T, Kudo M, Hirooka M, Tsuji K, Itobayashi E, Kariyama K, Ishikawa T, Tajiri K, Ochi $\mathrm{H}$, et al: Albumin-Bilirubin (ALBI) grade as part of the evidence-based clinical practice guideline for HCC of the Japan society of hepatology: A comparison with the liver damage and child-pugh classifications. Liver Cancer 6: 204-215, 2017.

8. Miyagawa S, Makuuchi M, Kawasaki S and Kakazu T: Criteria for safe hepatic resection. Am J Surg 169: 589-594, 1995.

9. Shiina S, Tateishi R, Arano T, Uchino K, Enooku K, Nakagawa H, Asaoka Y, Sato T, Masuzaki R, Kondo Y, et al: Radiofrequency ablation for hepatocellular carcinoma: 10-year outcome and prognostic factors. Am J Gastroenterol 107: 569-577; quiz 578, 2012.

10. Hiraoka A, Michitaka K, Horiike N, Hidaka S, Uehara T, Ichikawa S, Hasebe A, Miyamoto Y, Ninomiya T, Sogabe I, et al: Radiofrequency ablation therapy for hepatocellular carcinoma in elderly patients. J Gastroenterol Hepatol 25: 403-407, 2010.

11. Llovet JM, Ricci S, Mazzaferro V, Hilgard P, Gane E, Blanc JF, de Oliveira AC, Santoro A, Raoul JL, Forner A, et al: Sorafenib in advanced hepatocellular carcinoma. N Engl J Med 359: 378-390, 2008

12. Bruix J, Qin S, Merle P, Granito A, Huang YH, Bodoky G, Pracht M, Yokosuka O, Rosmorduc O, Breder V, et al: Regorafenib for patients with hepatocellular carcinoma who progressed on sorafenib treatment (RESORCE): A randomised, double-blind, placebo-controlled, phase 3 trial. Lancet 389: 56-66, 2017.

13. Kudo M, Finn RS, Qin S, Han KH, Ikeda K, Piscaglia F, Baron A, Park JW, Han G, Jassem J, et al: Lenvatinib versus sorafenib in first-line treatment of patients with unresectable hepatocellular carcinoma: A randomised phase 3 non-inferiority trial. Lancet 391: 1163-1173, 2018.

14. Hiraoka A, Kumada T, Kariyama K, Takaguchi K, Itobayashi E, Shimada N, Tajiri K, Tsuji K, Ishikawa $\mathrm{T}$, Ochi $\mathrm{H}$, et al: Therapeutic potential of lenvatinib for unresectable hepatocellular carcinoma in clinical practice: Multicenter analysis. Hepatol Res 49: 111-117, 2019.

15. Bolondi L, Sofia S, Siringo S, Gaiani S, Casali A, Zironi G, Piscaglia F, Gramantieri L, Zanetti M and Sherman M: Surveillance programme of cirrhotic patients for early diagnosis and treatment of hepatocellular carcinoma: A cost effectiveness analysis. Gut 48: 251-259, 2001.

16. Tanaka H, Nouso K, Kobashi H, Kobayashi Y, Nakamura S, Miyake Y, Ohnishi H, Miyoshi K, Iwado S, Iwasaki Y, et al: Surveillance of hepatocellular carcinoma in patients with hepatitis $C$ virus infection may improve patient survival. Liver Int 26: 543-551, 2006.

17. Makuuchi M, Kokudo N, Arii S, Futagawa S, Kaneko S, Kawasaki S, Matsuyama Y, Okazaki M, Okita K, Omata M, et al: Development of evidence-based clinical guidelines for the diagnosis and treatment of hepatocellular carcinoma in Japan. Hepatol Res 38: 37-51, 2008.

18. Kokudo N, Hasegawa K, Akahane M, Igaki H, Izumi N, Ichida T, Uemoto S, Kaneko S, Kawasaki S, Ku Y, et al: Evidence-based clinical practice guidelines for hepatocellular carcinoma: The Japan society of hepatology 2013 update (3rd JSH-HCC Guidelines). Hepatol Res 45, 2015.

19. Sano K, Ichikawa T, Motosugi U, Sou H, Muhi AM, Matsuda M, Nakano M, Sakamoto M, Nakazawa T, Asakawa M, et al: Imaging study of early hepatocellular carcinoma: Usefulness of gadoxetic acid-enhanced MR imaging. Radiology 261: 834-844, 2011.

20. Bruix J and Sherman M; Practice Guidelines Committee, American Association for the Study of Liver Diseases: Management of hepatocellular carcinoma. Hepatology 42: 1208-1236, 2005. 
21. Hiraoka A, Hiasa Y, Onji M and Michitaka K: New contrast enhanced ultrasonography agent: Impact of Sonazoid on radiofrequency ablation. J Gastroenterol Hepatol 26: 616-618, 2011.

22. Hiraoka A, Ichiryu M, Tazuya N, Ochi H, Tanabe A, Nakahara H, Hidaka S, Uehara T, Ichikawa S, Hasebe A, et al: Clinical translation in the treatment of hepatocellular carcinoma following the introduction of contrast-enhanced ultrasonography with Sonazoid. Oncol Lett 1: 57-61, 2010.

23. The Liver Cancer Study Group of Japan. The general rules for the clinical and pathological study of primary liver cancer. 6th edition. Kanehara, Tokyo 26, 2015.

24. Kanda Y: Investigation of the freely available easy-to-use software 'EZR' for medical statistics. Bone Marrow Transplant 48 : 452-458, 2013.

25. Kan M, Hiraoka A, Uehara T, Hidaka S, Ichiryu M, Nakahara H, Ochi H, Tanabe A, Kodama A, Hasebe A, et al: Evaluation of contrast-enhanced ultrasonography using perfluorobutane [Sonazoid(®)] in patients with small hepatocellular carcinoma: Comparison with dynamic computed tomography. Oncol Lett 1: $485-488,2010$

26. Hiraoka A, Horiike N, Yamashita Y, Koizumi Y, Doi K, Yamamoto Y, Hasebe A, Ichikawa S, Yano M, Miyamoto Y, et al: Efficacy of radiofrequency ablation therapy compared to surgical resection in 164 patients in Japan with single hepatocellular carcinoma smaller than $3 \mathrm{~cm}$, along with report of complications. Hepatogastroenterology 55: 2171-2174, 2008.

27. Hirooka M, Iuchi H, Kumagi T, Shigematsu S, Hiraoka A, Uehara T, Kurose K, Horiike N and Onji M: Virtual sonographic radiofrequency ablation of hepatocellular carcinoma visualized on CT but not on conventional sonography. AJR Am J Roentgenol 186 (5 Suppl): S255-S260, 2006.

28. Uehara T, Hirooka M, Ishida K, Hiraoka A, Kumagi T, Kisaka Y, Hiasa Y and Onji M: Percutaneous ultrasound-guided radiofrequency ablation of hepatocellular carcinoma with artificially induced pleural effusion and ascites. J Gastroenterol 42: 306-311, 2007.

29. Singal AG, Conjeevaram HS, Volk ML, Fu S, Fontana RJ, Askari F, Su GL, Lok AS and Marrero JA: Effectiveness of hepatocellular carcinoma surveillance in patients with cirrhosis. Cancer Epidemiol Biomarkers Prev 21: 793-799, 2012.

30. Zhang BH, Yang BH and Tang ZY: Randomized controlled trial of screening for hepatocellular carcinoma. J Cancer Res Clin Oncol 130: 417-422, 2004.

31. Chen JG, Parkin DM, Chen QG, Lu JH, Shen QJ, Zhang BC and Zhu YR: Screening for liver cancer: Results of a randomised controlled trial in Qidong, China. J Med Screen 10: 204-209, 2003.
32. Costentin CE, Layese R, Bourcier V, Cagnot C, Marcellin P, Guyader D, Pol S, Larrey D, De Lédinghen V, Ouzan D, et al: Compliance with hepatocellular carcinoma surveillance guidelines associated with increased lead-time adjusted survival of patients with compensated viral cirrhosis: A multi-center cohort study. Gastroenterology 155: 431-442.e10, 2018.

33. Toyoda H, Kumada T, Tada T, Mizuno K, Hiraoka A, Tsuji K, Ishikawa T, Akita T and Tanaka J: Impact of hepatocellular carcinoma aetiology and liver function on the benefit of surveillance: A novel approach for the adjustment of lead-time bias. Liver Int 38: 2260-2268, 2018.

34. Tateishi R, Okanoue T, Fujiwara N, Okita K, Kiyosawa K, Omata M, Kumada H, Hayashi N and Koike K: Clinical characteristics, treatment, and prognosis of non- $\mathrm{B}$, non- $\mathrm{C}$ hepatocellular carcinoma: A large retrospective multicenter cohort study. J Gastroenterol 50: 350-360, 2015.

35. Urata Y, Yamasaki T, Saeki I, Iwai S, Kitahara M, Sawai Y, Tanaka K, Aoki T, Iwadou S, Fujita N, et al: Clinical characteristics and prognosis of non-B non-C hepatocellular carcinoma patients with modest alcohol consumption. Hepatol Res 46: 434-442, 2016.

36. Hiraoka A, Ochi M, Matsuda R, Aibiki T, Okudaira T, Kawamura T, Yamago H, Nakahara H, Suga Y, Azemoto N, et al: Ultrasonography screening for hepatocellular carcinoma in Japanese patients with diabetes mellitus. J Diabetes 8: 640-646, 2016.

37. Kolly P and Dufour JF: Surveillance for hepatocellular carcinoma in patients with NASH. Diagnostics (Basel) 6: pii: E22, 2016.

38. Sterling RK, Lissen E, Clumeck N, Sola R, Correa MC, Montaner J, S Sulkowski M, Torriani FJ, Dieterich DT, Thomas DL, et al: Development of a simple noninvasive index to predict significant fibrosis in patients with HIV/HCV coinfection. Hepatology 43: 1317-1325, 2006.

39. Vallet-Pichard A, Mallet V, Nalpas B, Verkarre V, Nalpas A, Dhalluin-Venier V, Fontaine $\mathrm{H}$ and Pol S: FIB-4: An inexpensive and accurate marker of fibrosis in HCV infection. Comparison with liver biopsy and fibrotest. Hepatology 46: 32-36, 2007.

40. Smajerova M, Petrasova H, Little J, Ovesna P, Andrasina T, Valek V, Nemcova E and Miklosova B: Contrast-enhanced ultrasonography in the evaluation of incidental focal liver lesions: A cost-effectiveness analysis. World J Gastroenterol 22: 8605-8614, 2016.

41. Ogawa C, Minami Y, Morioka Y, Noda A, Arasawa S, Izuta M, Kubo A, Matsunaka T, Tamaki N, Shibatouge M and Kudo M: Virtual sonography for novice sonographers: Usefulness of SYNAPSE VINCENT ${ }^{\circledR}$ with pre-check imaging of tumor location. Oncology 87 (Suppl 1): S50-S54, 2014. 